\title{
Adsorptive Removal of Arsenic (III) From Aqueous Solution using Chemically-Modified Sweet Lime (Citrus limetta) Peels
}

\author{
Subarna Karki ${ }^{1}$, Ram Lochan Aryal $^{2}$, Sitaram Bhattarai ${ }^{l}$, Surendra Kumar Gautam ${ }^{I}$ and \\ Bhoj Raj Poudel ${ }^{\text {** }}$ \\ ${ }^{I}$ Department of Chemistry, Tri-Chandra Multiple Campus, Tribhuvan University, Nepal \\ ${ }^{2}$ Department of Chemistry, Amrit Campus, Tribhuvan University, Nepal \\ E-mail: bhojrajpoudel@yahoo.com
}

\begin{abstract}
The adsorption of arsenic(III) ions from aqueous media was studied using raw Citrus limetta peel (RCLP) and chemically modified Citrus limetta peel (CMCLP) by batch equilibrium method. The effects of initial metal ion concentration, contact time, adsorption dose and $\mathrm{pH}$ were studied. The maximum removal of As(III) was achieved at $p H 9$ for both RCLP and CMCLP at optimum contact time of 4 hrs and 5 hrs respectively at initial concentration of $20 \mathrm{mg} / \mathrm{L}$. The maximum As(III) removal were found to be $198.95 \mathrm{mg} / \mathrm{g}$ and $274 \mathrm{mg} / \mathrm{g}$ for RCLP and CMCLP respectively. Freundlich isotherm and pseudo second order kinetic model showed better explanation for adsorption process. The adsorbent was characterized by FT-IR, XRD and Boehm titration. The results showed that RCLP and CMCLP has a great potential for removal of As(III) ion.
\end{abstract}

Key words: Arsenic(III), Biosorption, Isotherm, Kinetics

\section{Introduction}

Arsenic is a highly toxic and carcinogenic metalloid and naturally occurring contaminant of surface water and ground water. It is considered as one of the oldest and dangerous poisonous having various effect on human health. Is notorious as king of all poisons ${ }^{1}$. It rank $20^{\text {th }}$ element in natural abundance in earth crust and widely distributed in earth at concentration of nearly $2 \mathrm{mg} / \mathrm{kg}^{-1} .{ }^{2}$ The name of arsenic(As) is derived from Greek word arsenikon means yellow orpiment. Arsenic exists in different oxidation state as $-3,+3,0$ and $+5^{3}$ Two forms are common in natural waters; arsenite $\left(\mathrm{AsO}_{3}{ }^{-3}\right)$ as arsenic (III) and arsenate $\left(\mathrm{AsO}_{4}^{-3}\right)$ as arsenic $(\mathrm{V})^{5}$. Arsenic(III) is about 60 times more toxic than $\operatorname{arsenic}(\mathrm{V})$. Environmental forms of arsenic may be arsenious acids $\left(\mathrm{H}_{3} \mathrm{AsO}_{4}, \mathrm{H}_{3} \mathrm{AsO}_{4}^{-}, \mathrm{H}_{3} \mathrm{AsO}_{2}^{-2}\right)$, arshine, methyl arsenic acids, etc.

Geogenic and anthropogenic processes like mining, smelting, coal combustion, leather tanning has led to arsenic contamination of water resources. World Health Organisation (WHO) has set the guideline value for arsenic in drinking water as $10 \mathrm{ppb}$ or $0.1 \mathrm{mg} / \mathrm{L}^{5} \mathrm{Nepal}$ has fixed $50 \mathrm{ppb}$ arsenic guideline value as standard in drinking water ${ }^{6}$. Once arsenic has entered to environment, it cannot be destroyed, it spread and cause health effects to humans and animals. Human may exposed to arsenic through food, water, air and skin contact with soil and water that contains arsenic. The contamination of arsenic in drinking water have raised serious problem on human health ${ }^{7}$. Health effects are melanosis, keratosis, weakness,

* Corresponding author 


\section{J. Nepal Chem. Soc., Vol.37, 2017}

anaemia, burning sensation of eyes, swelling of feet and legs, chronic lung disease, kidney and liver failure, skin cancer, lymphatic cancer, heart disruptions, gangrene of parts of body etc, ${ }^{8,9,10}$.

The various techniques such as ion-exchange, coagulation, reverse osmosis, membrane technologies, biosorption are used for removing arsenic from aqueous solution. In comparison to convention remediation techniques, biosorption has been significant progression in recent years due to its low cost, imple, easy to operate and eco-friendly ${ }^{11}$. The present study is aimed to develop a cost effective and locally available biosorbent Citrus limetta peel to remove arsenic ions by biosorption from arsenic contaminated water. The sorption parameters are $\mathrm{pH}$, contact time, dosage and initial concentration. The nature of sorption are in terms of Langmuir and Freundlich isotherm model and rate kinetics were also determined.

\section{Experimental Methods}

All chemicals used in present experiment were of analytical reagent and were used without any further purification. Arsenic trioxide $\left(\mathrm{As}_{2} \mathrm{O}_{3}\right)$ was used to prepare the stock solution (1000 ppm) of arsenic (III) from which dilutions were prepared for working solutions using distilled water. The $\mathrm{pH}$ of the experimental solutions were maintained by using $\mathrm{HCl}$ and $\mathrm{NaOH}$ solutions.

Fruit peel of Citrus limetta biomass was collected from local fruit shop located at New Baneshwor, Kathmadu, Nepal and washed thoroughly with distilled water. Then, it was dried in sunlight 5 days to remove moisture. The dried Citrus limetta peels were grinded into powder by using mechanical grinder at Central Department of Chemistry and sieved to particle size of $150 \mu \mathrm{m}$. The obtained powder is named as raw Citrus limetta peel (RCLP). For chemical modification $50 \mathrm{~g}$ of RCLP was treated with $100 \mathrm{ml}$ Conc. Sulphuric acid in a beaker to accomplish charring reaction. The suspension was left for 48 hours at room temperature for complete charring reaction. Then suspension was washed distilled water till the $\mathrm{pH}$ becomes neutral. Thus obtained solid adsorbent was dried at $60^{\circ} \mathrm{C}$ in hot air oven for 6 hours and sieved to pass through the particle of $150 \mu \mathrm{m}$ sieving device. The obtained powder is known as chemically modified Citrus limetta peel (CMCLP). Then powdered RCLP and CMCLP was stored in air tight clean and dry plastic bottle for further use in biosorption experiments. The possible mechanism for the charring process of monomeric unit of cellulose is shown below. ${ }^{1}$
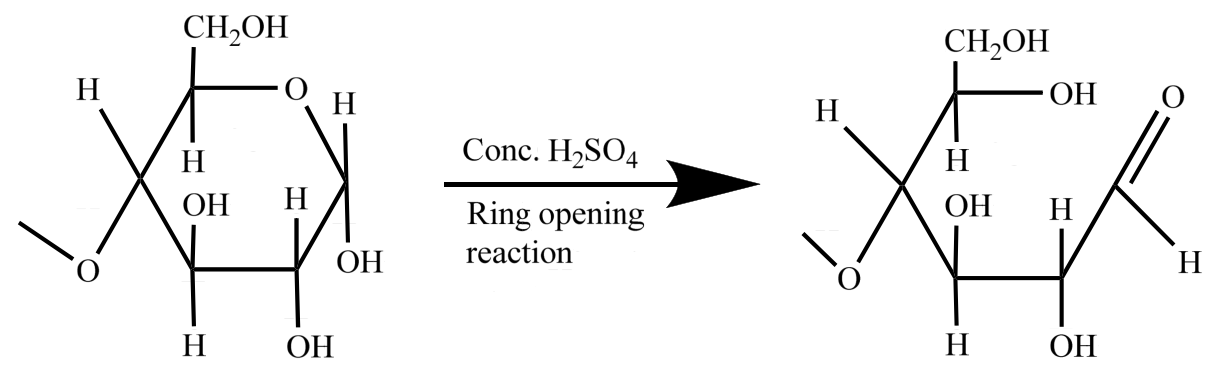

Figure 1: Plausible mechanism for the charring process of monomeric unit of cellulose.

\section{Batch sorption studies}

The adsorption experiments were studied by using batch sorption experiments. All the experiments were performed at room temperature and $150 \mathrm{rpm}$ on a mechanical shaker in $125 \mathrm{ml}$ plastic reagent 
bottle. The effect of $\mathrm{pH}$, amount of adsorbent, contact time and initial concentration were studied. After adsorption, the mixture was filtered through Whatman filter paper and filtrate were analysed for the determination of equilibrium concentration. The concentration of As(III) in solution before and after adsorption were analysed by using spectrophotometer.

Percentage removal is given by ${ }^{1}$,

$$
\text { Removal percentage }=\frac{\mathrm{Ci}-\mathrm{Ce}}{\mathrm{Ci}} \times 100 \%
$$

Where, $C_{i}=$ initial concentration of adsorbate $(\mathrm{mg} / \mathrm{L}), \mathrm{C}_{\mathrm{e}}=$ equilibrium concentration of adsorbate $(\mathrm{mg} / \mathrm{L})$

The amount of adsorbate in $\mathrm{mg} / \mathrm{g}$ at equilibrium is determined by using following equation ${ }^{1}$.

$$
\mathrm{q}=\frac{(\mathrm{Ci}-\mathrm{Ce}) \mathrm{V}}{W} \mathrm{mg} / \mathrm{g}
$$

Where, $w=$ weight of adsorbent $(\mathrm{g}), \mathrm{C}_{\mathrm{i}}=$ initial concentration of adsorbate $(\mathrm{mg} / \mathrm{L}), \mathrm{C}_{\mathrm{e}}=$ equilibrium concentration of adsorbate $(\mathrm{mg} / \mathrm{L}), \mathrm{v}=$ volume of adsorbate

\section{Results and Discussions}

\section{Effect of pH}

The $\mathrm{pH}$ of the solution is one of the most important factor in controlling Asbiosorption. Figure 2 shows that maximum adsorption of As(III) occurred at $\mathrm{pH} 9$ for both RCLP and CMCLP and $\mathrm{pH} 9$ is designated as optimum $\mathrm{pH}$. Maximum adsorption percentage was found to be $70.1 \%$ for RCLP and $84.75 \%$ for CMCLP.

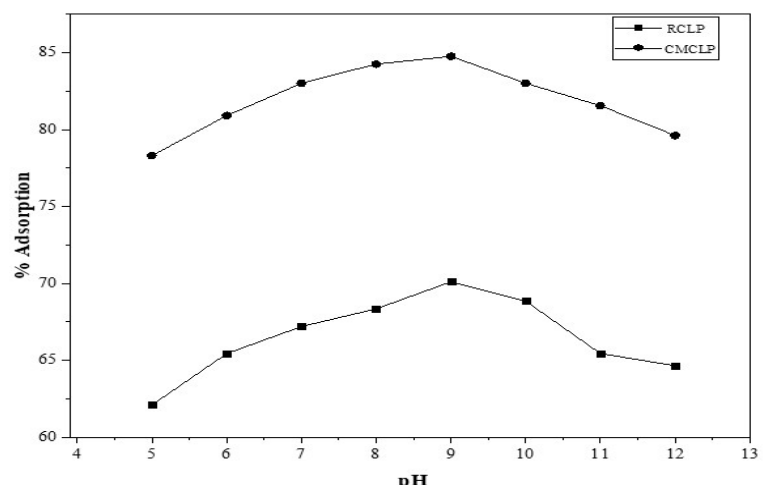

Figure 2: Effect of $p H$ on the adsorption of As(III) onto RCLP and CMCLP

It was found that the arsenic adsorption was lower at lower $\mathrm{pH}$, attained maximum at $\mathrm{pH} 9$ and declined with increase in $\mathrm{pH}$ for both RCLP and CMCLP. This increase ordecrease in adsorption capacity with $\mathrm{pH}$ is due to surface functional charge of the adsorbent, the degree of ionization and the specification of surface functional group.

\section{Effect of adsorbent dose}

The effect of adsorbent dose on the adsorption efficiency of As(III) by RCLP and CMCLP are shown in figure 3. From figure it was observed that the adsorption of As(III) increases on increasing the adsorbent dose and the adsorption become almost constant after adsorbent dose $125 \mathrm{mg}$ for RCLP and 
$100 \mathrm{mg}$ for CMCLP at optimum $\mathrm{pH}$ 9. The increase in As(III) adsorption percentage with increase in adsorbent dose may be due to the greater availability of the exchangeable sites at higher dose of the adsorbent. At low adsorbent dose, the adsorbent surface becomes saturated with As(III) and the corresponding residual As(III) ion concentration in the solution is large.

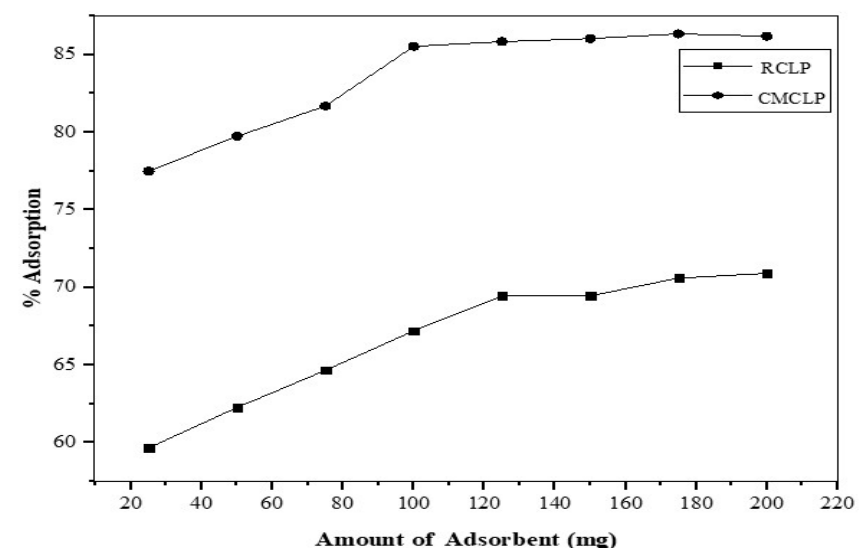

Figure 3: Effect of adsorbent dose on the adsorption of As(III) onto RCLP and CMCLP

\section{Effect of contact time}

Contact time studies were conducted between 0-24 hours on the batch adsorption of $20 \mathrm{mg} / \mathrm{L}$ As(III) with $25 \mathrm{mg}$ of adsorbent. The percentage adsorption of arsenic at various contact time is plotted in figure 4 .

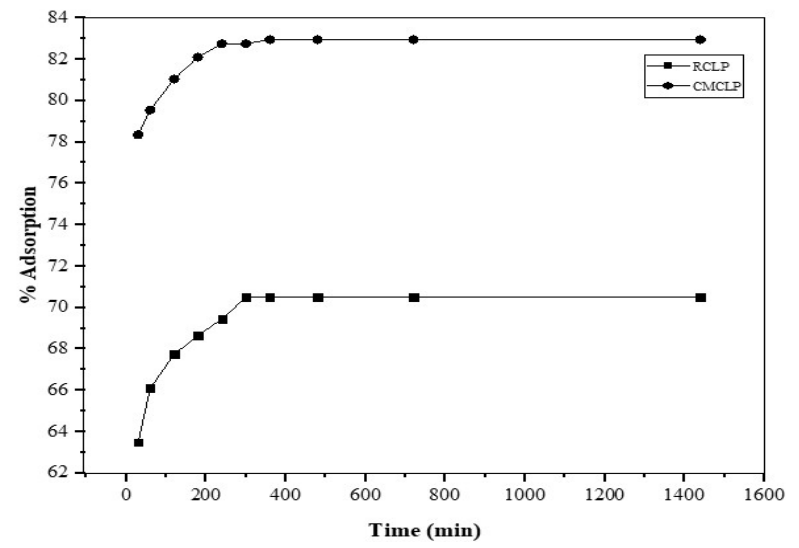

Figure 4: Effect of contact time for the adsorption of $\boldsymbol{A s}(\boldsymbol{I I I})$ onto RCLP and CMCLP

From figure it was observed that equilibrium time for RCLP was found to be 6 hour while that of CMCLP was found to be 5 hour at optimum $\mathrm{pH}$ 9.The arsenic adsorption capacity is rapid at first hour because of the presence of large number of anion exchange sites. When all the adsorption sites are occupied by As(III), the adsorption becomes constant.

\section{Effect of initial concentration}

The effect of As(III) concentration is shown in figure 5. 


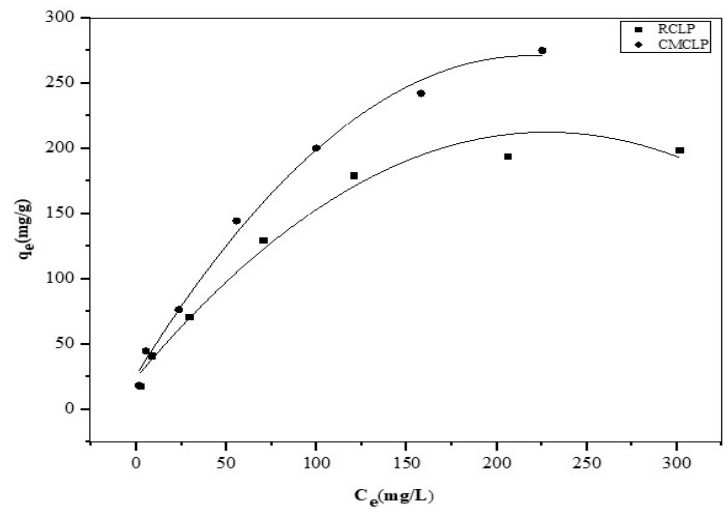

Figure 5: Effect of initial concentartion on the adsorption of As(III) onto RCLP and CMCLP

From figure it was cleared that the adsorption of As(III) increaseswith an increase in initial concentration of As(III) solution and attained an equilibrium after which the adsorbent becomes all most constant. The equilibrium concentration for RCLP was found to be $198.95 \mathrm{mg} / \mathrm{g}$ while that of CMCLP was found to be $274.89 \mathrm{mg} / \mathrm{g}$ at optimum $\mathrm{pH}$ 9. The increase in concentration of As(III) increases the mass transfer driving force and as a result increases the rate at which As(III) oxyanions pass from the bulk solution to the particle surface which consequently increases adsorption.

\section{Adsorption isotherm}

The experimental data for the adsorptive removal of As(III) from aqueous media was analysed by using Langmuir and Freundlich isotherm model as shown in figure 6 and 7.

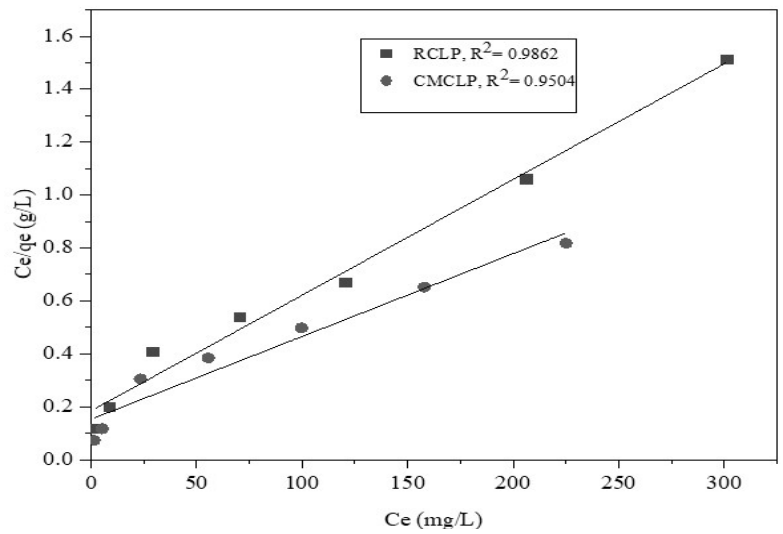

Figure 6: Langmuir isotherm for adsorption of As(III) onto RCLP and CMCLP 


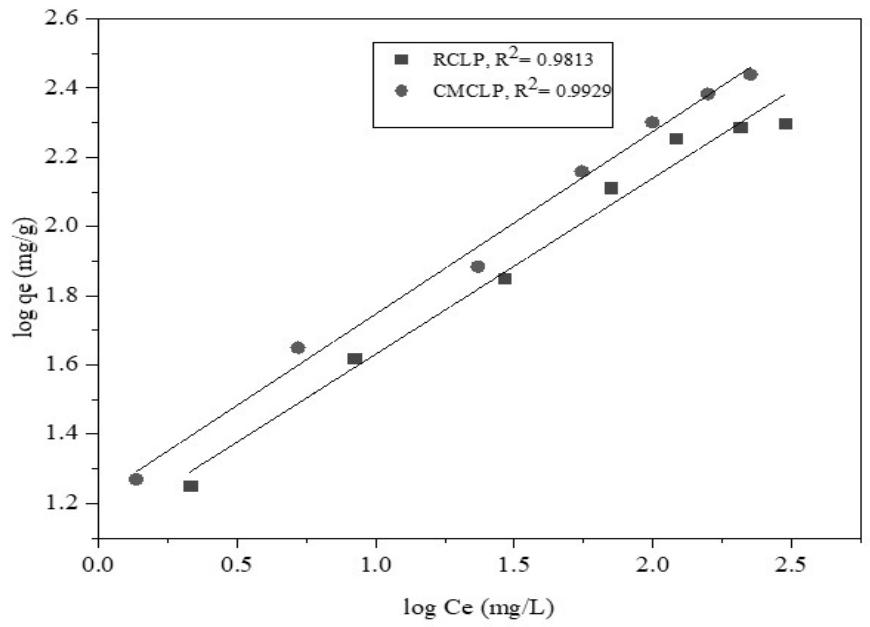

Figure 7: Freundlich isotherm plot for the adsorption of As(III) onto RCLP and CMCLP

Constant parameters and correlation coefficient values of each model obtained are given in table 1.

Table 1: Langmuir and Freundlich parameters for the adsorption of As(III) onto RCLP and CMCLP

\begin{tabular}{|c|c|c|c|c|c|c|c|c|}
\hline \multirow[t]{2}{*}{ Adsorbent } & \multirow{2}{*}{$\begin{array}{l}\operatorname{Exp} . q_{m} \\
\mathrm{mg} / \mathrm{g}\end{array}$} & \multicolumn{4}{|c|}{ Langmuir isotherm } & \multicolumn{3}{|c|}{ Freundlich isotherm } \\
\hline & & $\mathbf{q}_{m}(\mathrm{mg} / \mathrm{g})$ & b $(\mathrm{mg} / \mathrm{L})$ & $\mathbf{R}^{2}$ & $\mathbf{R}_{\mathbf{L}}$ & $\mathrm{K}(\mathrm{mg} / \mathrm{g})$ & $1 / n$ & $\mathbf{R}^{2}$ \\
\hline RCLP & 198.95 & 227.27 & 0.023 & 0.98 & 0.68 & 13.28 & 0.50 & 0.98 \\
\hline CMCLP & 274.89 & 322.58 & 0.020 & 0.95 & 0.19 & 16.58 & 0.52 & 0.99 \\
\hline
\end{tabular}

The $\mathrm{R}_{\mathrm{L}}$ value lie between 0 and 1 that indicates equilibrium data fits well with Langmuir adsorption isotherm. The values of $1 / \mathrm{n}$ lies between 0 and 1 in Freundlich isotherm indicates the adsorption process is favourable. The comparison between correlation coefficient values $\left(\mathrm{R}^{2}\right)$ of Langmuir and Freundlich adsorption isotherm indicate that Freundlich adsorption isotherm is better than Langmuir adsorption isotherm which indicates heterogeneous distribution of active sites on the adsorbent surface.

\section{Kinetic Studies}

Kinetic studies for the adsorptionof As(III) onto RCLP and CMCLP were studied using pseudofirst order, pseudosecond order and second order models. From the kinetics plots of As(III) for the adsorption it was observed that the correlation coefficients $\left(\mathrm{R}^{2}\right)$ for pseudo second order were found to be higherthan that of pseudofirst order and second order kinetics. The adsorption of As(III) onto RCLP and CMCLP follows pseudo second order kinetic model which is shown in figure 8 . 


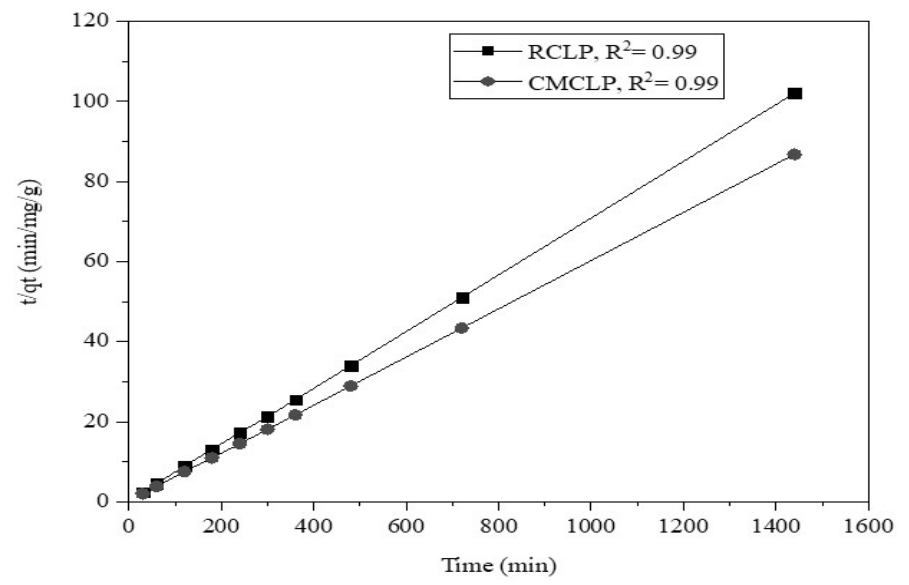

Figure 8:Pseudo second order kinetic model for adsorption of As(III) onto RCLP and CMCLP

\section{Sample Characterization}

\section{FT-IR analysis}

The FT-IR spectra of biosorbent before and after As(III) binding were analyzed in the range of 400$4000 \mathrm{~cm}^{-1}$. The examination of adsorbent before and after sorption reaction possibly provides information regarding the surface functional groups that might have participated in the adsorption reaction and also indicates the surface sites on which adsorption has taken place.FTIR spectrum analysis was conducted at Department of Chemistry, Kirtipur, Kathmandu, which are shown in figure 9.

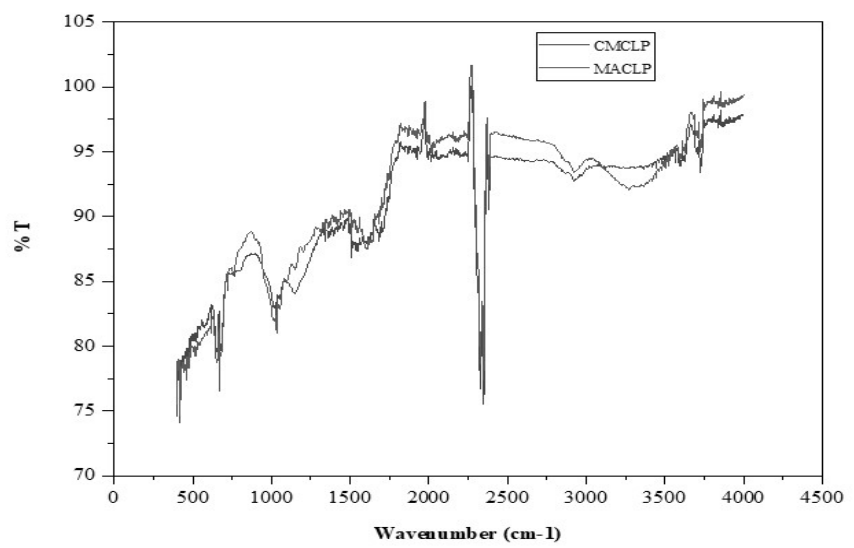

Figure 9: FT-IR spectrum of CMCLP and Metal adsorbed Citrus limetta peel (MACLP)

The broad peak $3288 \mathrm{~cm}^{-1}$ indicating presence of hydroxyl groups of macromolecular association (cellulose, pectin, etc.). The characteristics band at $2930 \mathrm{~cm}^{-1}$ indicates $\mathrm{CH}-$ stretching vibration of methylene and methoxy group. Carboxylic acids salts shows characteristic stretching vibration at 1620 $\mathrm{cm}^{-1}$. The peak around $1024-1150 \mathrm{~cm}^{-1}$ were due to presence of $-\mathrm{CN}$ and $\mathrm{C}-\mathrm{C}$ stretching. 


\section{J. Nepal Chem. Soc., Vol.37, 2017}

The FT-IR spectra of optimized sample shows the significant shift in intensity and frequency range of carboxyl and hydroxyl stretches and appearance of new peaks and disappearance of some peak. The change in intensity and appearance of new peaks can be attributed to the binding of metal ions to the functional group, while absence of peak indicates the involvement of chemical reaction, leading to decomposition of chemical bonds. The broadening of peak at $3288 \mathrm{~cm}^{-1}$ indicates presence of $-\mathrm{NH}$ and $\mathrm{OH}$ functional group bounded.

\section{XRD analysis}

The XRD pattern of biosorbent are given in figure 10. In the figure, sharp peak was not obtained, it suggests that the structure of adsorbent is not crystalline rather than it is amorphous on nature. Due to amorphous nature of biosorbent, is has good adsorption capacity.

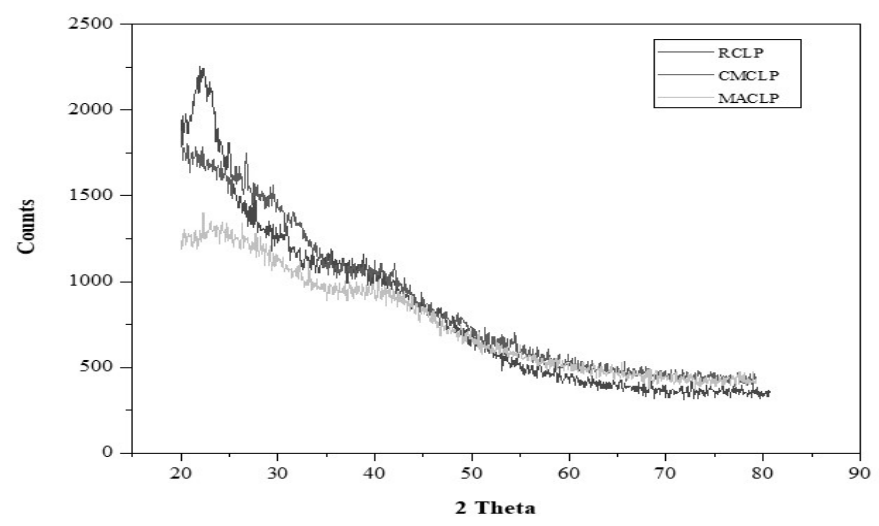

Figure 3.19: XRD Pattern for RCLP, CMCLP and MACLP

\section{Boehm titration}

The surface chemical properties of biosorbent was characterized by using Boehm technique method for both RCLP and CMCLP. Basically surface functional groups containing oxygen were determined according to Boehm titration. The properties of the surface functional group through the Boehm titration is summarized in table 2. The increase in acidic group suggest that the majority of the functional group on the adsorbent surface are acidic. The more aciditygroups indicating present of more oxygenated functional groups which give rise to higher adsorption of heavy metals.

Table 2: Boehm titration data for RCLP and CMCLP

\begin{tabular}{|c|c|c|}
\hline Biosorbent & \multicolumn{2}{|c|}{ Boehm's titration method } \\
\hline & Acidic $(\mathrm{mmol} / \mathrm{g})$ & Basic $(\mathrm{mmol} / \mathrm{g})$ \\
\hline RCLP & 0.034 & 0.035 \\
\hline CMCLP & 0.050 & 0.024 \\
\hline
\end{tabular}




\section{Conclusions}

In the present work, the removal of As(III) from locally availiable low cost adsorbent, Citrus limetta peel and its chemically modified form were investigated and their efficiency was compared by varying different parameters. The optimum adsorption capacity was achieved atpH 9 for both RCLP and CMCLP at initial concentration of $20 \mathrm{mg} / \mathrm{L}$. The equilibrium time for the biosorption of As(III) onto RCLP and CMCLP were found to be 6 hour and 5 hour respectively. The optimum doses of RCLP and CMCLP for adsorption of As(III) were $125 \mathrm{mg}$ and $100 \mathrm{mg}$ respectively. The maximum adsorption capacityof RCLP and CMCLP were found to be $198.95 \mathrm{mg} / \mathrm{L}$ and $274.89 \mathrm{mg} / \mathrm{L}$ respectively. The adsorption data were tested for both Langmuir and Freundlich adsorption isotherm model. From kinetic data, the best fitting model is pseudo-second order. Functional group present in biosorbent was characterized by FT-IR analysis and Boehm titration and sample was also characterized by XRD. From this work. it can be concluded that RCLP and CMCLP are suitable biosorbent for adsorption of As(III) from water with high efficiency and rapid uptake capacity. Furthermore, it is clear that chemical modification increases the efficiency of adsorption.

\section{Acknowledgements}

The authors are grateful to the Department of Chemistry, Tri-Chandra Multiple Campus, Tribhuvan University, Ghantaghar, Kathmandu for providing the available research facilities to conduct this work. The authors are also thankful to Central department of Chemistry, Tribhuvan University, Kirtipur, Kathmandu for providing FT-IR spectra and grinding machine and XRD spectra from NAST, Khumaltar, Kathmandu, Nepal.

\section{References}

1. H. C.Thakuri, M.R.Pokhrel, K.N.Ghimire, D.B.Khadka, Res. J. Chem.Sci., 2015, 5, 51-58.

2. S. Kamsonlian, S.Suresh, C.B. Majumder,S.Chand, Asian J. Chem., 2013, 25, 2409-2417.

3. J. Kour, P.L. Homagai, M.R.Pokhrel, K.N.Ghimire, Nep. J. Sci.Tech.,2012, 13, 101-106.

4. R.K.Mallampati, S.Valiyaveettil,American Chem.Soc.,2013, 5, 4443-4449.

5. S.Irem, E.Ialam, Q.M.Khan, M.A.Haq, A.J.Hashmet, Water Sci. Tech., Water Supply., 2017,17,1149-1159.

6. J.C.Ng, Environ.Chem.,2005, 2, 146-160.

7. P.Yuan, X.Hongyan, C.Xianzhong, C.Hongei, Adv. Mat. Res., 2013, 773, 889-892.

8. C.K.Jain, I.Ali, Water Res., 2000, 34, 4304-4312.

9. WHO (World Health Organisation): Enviromental Health Criteria, Arsenic, World Health Organisation, Geneva, 1981.

10. S. Kamsonlian, S.Suresh, C.B. Majumder,S.Chand, Asian J. Chem., 2013, 25, 2409-2417.

11. A. Muhammad, N.N.Khan, B.Irshad, F.Abida, S.O.Yong, K.Anitha, F.Ali, S.Ali, A.I.Deshani, A.Muhammad,Int. J. Phytro.,2016, 18, 442-449.

12. S. Regmi, K. N. Ghimire, M. R. Pokhrel, D. B. Khadka, JIST, 2015, 20(2),145-152 